\title{
Hearing Results of Tympanoplasties in I 75 Patients with Chronic Otitis Media
}

\author{
Yong Soo Jeong, Hi Boong Kwak, Yeo Jin Lee, Mun Su Park, \\ Jae Myeong Kim, Jung Eun Shin and Hong Ju Park \\ Department of Otorhinolaryngology-Head and Neck Surgery, Konkuk University School of Medicine, Seoul, Korea
}

\section{만성 중이염 175 명 환자의 고실성형술에 의한 청력 결과}

정용수 · 곽희붕 - 이여진 · 박문수 · 김재명 · 신정은 · 박홍주

건국대학교 의학전문대학원 이비인후-두경부외과학교실

\section{Received June 10, 2009 \\ Revised September 16, 2009 \\ Accepted September 18, 2009}

Address for correspondence

Hong Ju Park, MD, PhD

Department of Otorhinolaryngology-

Head \& Neck Surgery,

Konkuk University

School of Medicine,

4-12 Hwayang-dong, Gwangjin-gu,

Seoul 143-729, Korea

Tel $+82-2-2030-7663$

Fax +82-2-2030-7749

E-mail hpark@kuh.ac.kr

Background and Objectives To report the hearing results of tympanoplasty for chronic otitis media with or without cholesteatoma.

Subjects and Method One hundred and seventy-five patients presenting chronic otitis media with or without cholesteatoma were involved in a retrospective study. Tympanoplasties were performed by the same surgeon over a 30-month period. Audiometric results were reviewed. Audiometric results according to the following techniques were measured: tympanoplasty type $1(\mathrm{~T} 1)$, interposition $(\mathrm{Si})$ and/or columella $(\mathrm{Sc})$ over stapedial head, and interposition or columella (Fic) over footplate. The follow-up period ranged from 6 to 32 months. Audiological parameters using the average of four frequencies were assessed pre- and post-operatively.

Results Overall hearing results showed postoperative air-bone gaps (ABG) $\leq 20 \mathrm{~dB}$ in $69 \%$ of cases. ABG was closed to within $20 \mathrm{~dB}$ in $89 \%$ for T1, $67 \%$ for Sc, $58 \%$ for $\mathrm{Si}$, and $30 \%$ for Fic. ABG was closed to within $30 \mathrm{~dB}$ in $95 \%$ for $\mathrm{T} 1,67 \%$ for $\mathrm{Sc}, 83 \%$ for $\mathrm{Si}$, and $70 \%$ for Fic. There was a significant improvement between preoperative and postoperative ABGs. The overall improvement of the air-bone gap was $8 \pm 13 \mathrm{~dB}$. There was no significant functional difference between different surgical techniques.

Conclusion Our hearing results after tympanoplasties were similar to those from other studies. The hearing results observed in this study confirmed that successful results can be obtained by applying the current principles and approach to ossicular reconstruction.

Korean J Otorhinolaryngol-Head Neck Surg 2009;52:880-4

Key Words Ossicular reconstruction · Ossiculoplasty $\cdot$ Tympanoplasty $\cdot$ Chronic otitis media.

\section{서 론}

중이염의 수술적 치료는 중이강이나 유양돌기의 염증성 병 변의 제거뿐 아니라 정상적인 이소골의 연쇄를 복원하는 것 이다. 1950년대 이후 고막의 재생과 이소골의 복원을 통하 여 청력의 복원을 시도하여 왔으며, 이후로 많은 수술 술식 과 이식 재료들이 개발되었다. ${ }^{1,2)}$ 본 연구에서는 이소골 연쇄 가 정상인 경우에 이소골 주위의 병변을 제거한 후 단순한 고 막의 천공을 막는 제 1 형 고실성형술을 시행한 경우와 이소
골 손상의 유형에 따라 다양한 고실성형술을 시행한 환자의 수술 후 청력 결과를 통하여 고실성형술에 의한 청력의 개선 효과를 알아보고자 하였다.

\section{대상 및 방법}

2006년부터 2008년까지 본원 이비인후과에서 일인 집도 의에 의해 만성 중이염으로 진단받고 유양동삭개술 및 고 실성형술을 시행 받은 환자의 의무기록을 후향적으로 검토 
하여 6개월 이상(6 32개월) 추적관찰하고 술 후 청력검사 를 시행한 175 예를 대상으로 하였다. 대상군은 모두 등골의 운동성이 양호한 상태였다. 제 1 형 고실성형술을 시행한 군 을 T1군으로 분류하였다. 등골 두부와 고막 사이에 지주를 세운 경우를 Sc (columella over stapes head) 군으로 분류, 등골 두부와 추골 사이에 지주를 세운 경우에는 $\mathrm{Si}$ (interposition over stapes head) 군으로 분류하였고, 등골 족판과 추 골 및 고막 사이에 지주를 세운 경우에는 Fic (interposition or columella over stapedial footplate)군으로 분류하였다. ${ }^{3)}$ 모 든 환자에서 지주로 사용한 인공구조물은 hydroxylapatite 로 만들어진 인공이소골(Gyrus ENT, Bartlett, TN, USA 또는 Medtronic-Xomed, Jacksonville, FL, USA)을 사용 하였다. 유양동삭개술은 수술 전에 시행한 전산화단층촬영 에서 유양동 내에 비가역적인 염증성 병변이 있을 경우 시행 하였으며, 이소골 연쇄가 정상인 환자에서는 제 1 형 고실성 형술을 시행하였다. 이소골연쇄가 손상된 환자 중 등골 상부 구조가 보존된 환자에서는 가능한 등골 두부와 추골병 사이 에 지주를 세우는 수술을 하도록 노력하였으며, 추골의 위치 가 부적합하여 등골 두부와 추골 사이에 지주를 세우기 힘들 거나 추골이 소실되었을 경우에는 등골 두부와 고막 사이에 지주를 세우는 수술을 시행하였다. 인공이소골과 고막 사이에 는 연골판을 삽입하는 연골간치술을 시행하였다. 등골 두부 가 손상된 경우에도 상기한 원칙에 의해 이소골 연쇄 재건을 시도(interposition or columella over stapes footplate, Fic) 하였으며, 이 환자군은 한 가지 군으로 통합하였다.

총 175 명 중 $\mathrm{T} 1$ 군은 82 명, Sc군은 3 명, Si군은 67 명, Fic군은 23명이었다. 대상 환자는 7 80세까지 고루 분포 하였으며 평균 나이는 45.8 세였다. 남녀비는 $1: 1.7$ 이었다. 청력검사는 술 전, 술 후 2 3, 6, 12개월에, 이후로는 1 년 에 한번씩 시행하였다. 본 연구에서는 술 후 최종 청력검사 결과의 기도-골도차(air-bone gap, $\mathrm{ABG}$ )를 이용하여 청 력 개선의 성공률을 검토하였다. 청력 개선의 성공은 술 후 $\mathrm{ABG}$ 이 $20 \mathrm{~dB}$ 이내인 경우 성공적인 결과, 20 30 dB 사 이는 변화 없음, $30 \mathrm{~dB}$ 보다 큰 경우는 나쁜 결과로 판정하였
다. 집단 간 청력 개선의 차이는 수술 전후 $\mathrm{ABG}$ 의 개선 정 도로 비교하였다. ${ }^{3)}$ 유양동삭개술의 동반 및 종류에 따른 청 력 개선 정도의 차이는 환자군이 충분한 $\mathrm{T} 1$ 군과 $\mathrm{Si}$ 군에서만 비교하였다. T1군에서 유양동삭개술의 동반이 청력 결과에 미치는 영향을 확인하기 위해 유양동삭개술의 동반 여부에 따른 청력 개선 정도의 차이를 평가하였으며, $\mathrm{Si}$ 군에서 폐쇄 형 및 개방형 유양동삭개술의 동반 여부에 따른 청력 개선 정 도의 차이를 평가하였다.

수술 전후의 $\mathrm{ABG}$ 의 비교는 $\mathrm{T} 1$ 군, $\mathrm{Si}$ 군과 $\mathrm{Fic}$ 군에서는 paired samples t-test, Sc군에서는 Wilcoxon signed ranks test를 사용하여 검정하였으며, 각 고실성형술의 방법에 따 른 $\mathrm{ABG}$ 의 개선 정도의 비교는 Kruskal-Wallis H test, $\mathrm{T} 1$ 군에서 유양동삭개술의 동반 여부에 따른 $\mathrm{ABG}$ 의 개선 정도의 비교와 $\mathrm{Si}$ 군에서 개방형 및 폐쇄형 유양동삭개술의 차이에 의한 $\mathrm{ABG}$ 의 개선 정도의 비교는 independent samples t-test를 사용하여 검정하였다(SPSS, version 14.0, SPSS Inc., Chicago, USA). 유의수준은 0.05 이하를 의미 있는 것으로 해석하였다.

\section{결 과}

총 175 명 및 각 집단의 유양동삭개술 및 고실성형술 분포 및 청력검사 결과는 Table 1 과 같다. 술 후 $\mathrm{ABG}$ 이 $20 \mathrm{~dB}$ 이하를 청력 개선의 성공으로 판단하고 이것을 기준으로 나 누었을 때 총 175 명 중 121 명(69\%)에서 성공적인 청력 개 선을 보였다. 각각의 집단 별로 살펴보았을 때 유양동삭개술 여부와 관계 없이 고실성형술만으로 구분하였을 때 $\mathrm{T} 1$ 군은 73명(89\%), Sc군에서는 2명(67\%), Si군에서는 39명(58\%), Fic군에서는 7 명 $(30 \%)$ 에서 성공적인 청력 개선을 보였다 (Fig. 1). 총 175 명의 수술 전 $\mathrm{ABG}$ 은 $24 \pm 13 \mathrm{~dB}$, 수술 후 $\mathrm{ABG}$ 은 $16 \pm 11 \mathrm{~dB}$ 이었다. T1군, Si군과 Fic군에서는 $\mathrm{ABG}$ 가 수술 전에 비해서 수술 후에 유의하게 감소하였으나 $(p<$ $0.001), \mathrm{Sc}$ 군에서는 유의한 $\mathrm{ABG}$ 의 차이를 보여주지 못하 였다 $(p=0.11$ ) (Fig. 2), 수술 후 $\mathrm{ABG}$ 가 수술 전 $\mathrm{ABG}$ 보다

Table 1. Summary of hearing results of tympanoplasties

\begin{tabular}{|c|c|c|c|c|c|c|c|c|c|c|c|}
\hline & \multirow{2}{*}{ No. } & \multicolumn{2}{|c|}{ Mastoidectomy } & \multirow{2}{*}{ T only } & \multirow{2}{*}{ Preop BC/AC } & \multirow{2}{*}{ Postop BC/AC } & \multirow{2}{*}{ Preop ABG } & \multirow{2}{*}{ Postop ABG } & \multirow{2}{*}{$\triangle A B G$} & \multirow{2}{*}{$\begin{array}{c}\% \text { postop } \\
A B G \leq 20 \mathrm{~dB}\end{array}$} & \multirow{2}{*}{$\begin{array}{c}\% \text { postop } \\
A B G \leq 30 \mathrm{~dB}\end{array}$} \\
\hline & & CWDM & CWUM & & & & & & & & \\
\hline $\mathrm{Tl}$ & 82 & 1 & 30 & 51 & $21 \pm 13 / 38 \pm 19$ & $20 \pm 14 / 31 \pm 19$ & $17 \pm 11$ & $11 \pm 9$ & $6 \pm 10$ & $89 \%$ & $95 \%$ \\
\hline Sc & 3 & 2 & 1 & 0 & $35 \pm 5 / 68 \pm 16$ & $31 \pm 13 / 54 \pm 26$ & $33 \pm 13$ & $24 \pm 13$ & $10 \pm 8$ & $67 \%$ & $67 \%$ \\
\hline $\mathrm{Si}$ & 67 & 34 & 27 & 6 & $28 \pm 13 / 56 \pm 18$ & $23 \pm 14 / 42 \pm 19$ & $28 \pm 13$ & $19 \pm 10$ & $8 \pm 16$ & $58 \%$ & $83 \%$ \\
\hline Fic & 23 & 17 & 2 & 4 & $25 \pm 14 / 59 \pm 14$ & $21 \pm 11 / 46 \pm 17$ & $34 \pm 10$ & $25 \pm 9$ & $9 \pm 13$ & $30 \%$ & $70 \%$ \\
\hline Total & 175 & 54 & 60 & 61 & $25 \pm 13 / 48 \pm 20$ & $21 \pm 14 / 37 \pm 20$ & $24 \pm 13$ & $16 \pm 11$ & $8 \pm 13$ & $69 \%$ & $87 \%$ \\
\hline
\end{tabular}

CWDM: canal-wall down mastoidectomy, CWUM: canal-wall up mastoidectomy, T: tympanoplasty, BC: bone-conduction hearing threshold, AC: air-conduction hearing threshold, ABG: air-bone gap, T1: tympanoplasty type 1, Sc: columella over stapedial head, Si: interposition over stapedial head, Fic: interposition or columella over footplate 


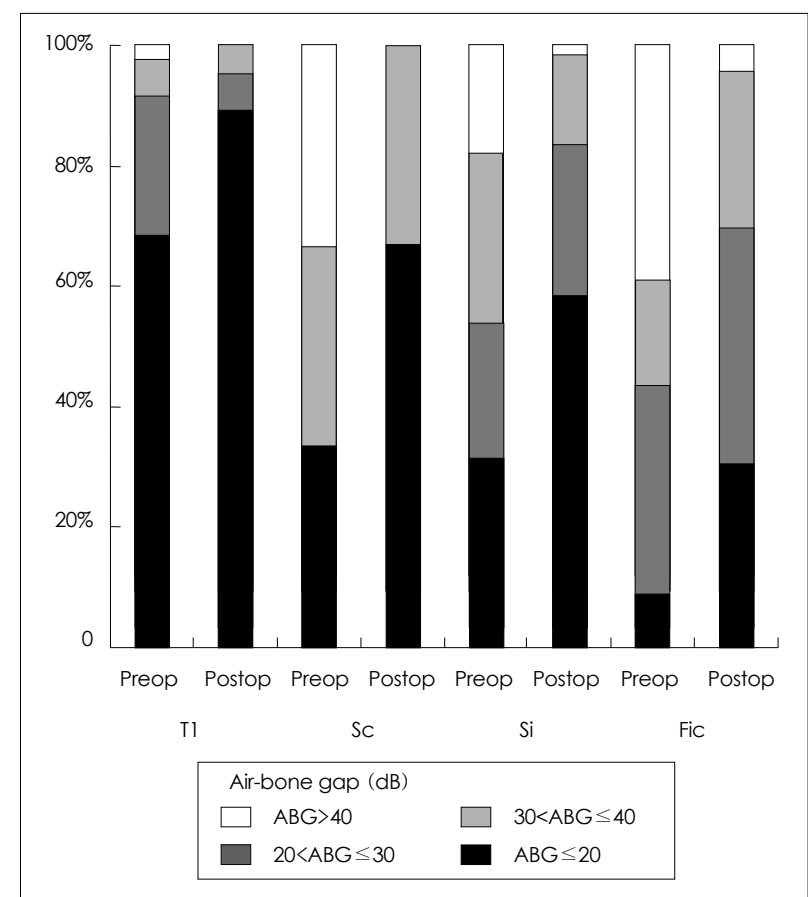

Fig. 1. Preoperative and postoperative air-bone gaps (ABG) for the types of tympanoplasties. T1: tympanoplasty type 1, Sc: columella over stapedial head, Si: interposition over stapedial head, Fic: interposition or columella over footplate.

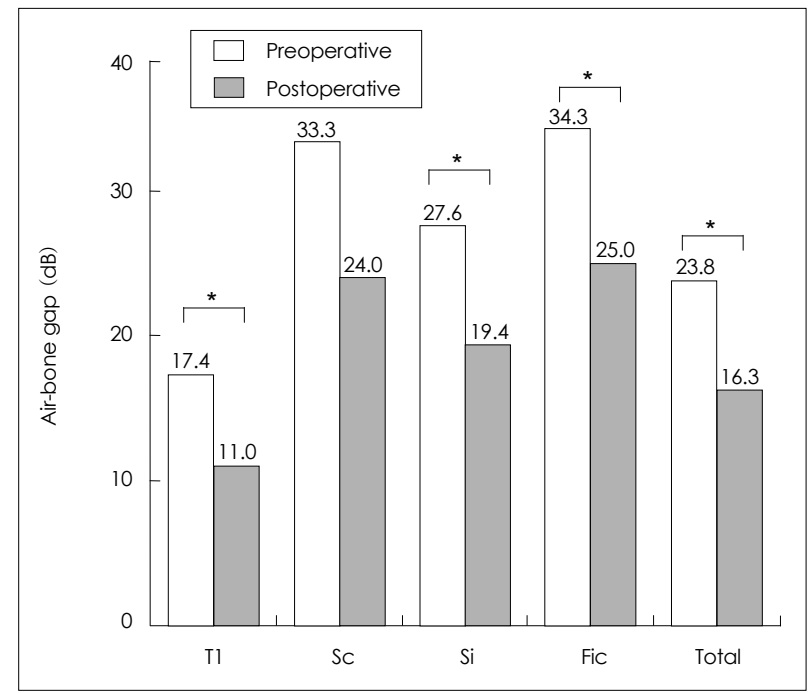

Fig. 2. Mean preoperative and postoperative air-bone gaps (ABG) for the types of tympanoplasties. $\star p<0.05$. T1: tympanoplasty type 1, Sc: columella over stapedial head, $\mathrm{Si}$ : interposition over stapedial head, Fic: interposition or columella over footplate.

$10 \mathrm{~dB}$ 이상 악화된 경우는 전체 175 명 중 13 명 $(7 \%)$ 에서 관찰되었으며, T1군에서는 3명 $(4 \%)$, Si군에서는 9명(14\%), Fic군에서는 1 명 $(4 \%)$ 이 관찰되었다. 수술 후 기도청력역치 가 수술 전과 비교하여 $10 \mathrm{~dB}$ 이상 악화된 환자는 11 명 (6\%)이었으며, T1군에서는 4명 $(5 \%), \mathrm{Si}$ 군에서는 7명(10\%) 에서 관찰되었다. 수술 후 고막의 천공이 발생한 경우는 14 명
(8\%)이었고, 인공이소골이 탈출된 경우는 $\mathrm{Si}$ 군에서 $6 \%$ (4명/67명)에서 발생하였고, 4명 중 3명에서 개방형 유양동 삭개술을 시행한 군이었다.

수술 전후 $\mathrm{ABG}$ 의 개선 정도로 고실성형술 간의 청력 개선 정도를 비교하였을 때 $\mathrm{T} 1$ 군은 $6.3 \pm 9.6 \mathrm{~dB}, \mathrm{Sc}$ 군은 $10.0 \pm$ $8.2 \mathrm{~dB}$, Si군은 $8.2 \pm 16.1 \mathrm{~dB}$, Fic군은 9.3 $\pm 13.2 \mathrm{~dB}$ 으로 고실성형술 방법에 따라 청력 개선 정도는 통계적 유의성은 보이지 않았다 $(p>0.05)$. T1군에서 유양동삭개술을 시행한 군 $(n=31)$ 과 시행하지 않은 군 $(n=51)$ 에서 청력 개선 정도 를 비교하였을 때 수술 전후의 $\mathrm{ABG}$ 의 개선 정도로 비교를 해보았을 때 유양동삭개술을 시행하지 않은 군에서의 $\mathrm{ABG}$ 의 개선 정도는 $6.8 \pm 8.8 \mathrm{~dB}$ 이었으며, 유양동삭개술을 시 행한 군에서는 $5.6 \pm 11.0 \mathrm{~dB}$ 로, 두 군 간에 통계적으로 차이 는 없었다 $(p=0.57) . \mathrm{Si}$ 군에서 폐쇄형 유양동삭개술을 시행 한 군 $(n=27)$ 과 개방형 유양동삭개술을 시행한 군 $(n=34)$ 에서 청력 개선 정도를 비교하였을 때 수술 전후 $\mathrm{ABG}$ 의 개 선 정도로 비교하면 폐쇄형 유양동삭개술을 시행한 군에서 의 $\mathrm{ABG}$ 의 개선 정도는 $10.3 \pm 14.6 \mathrm{~dB}$, 개방형 유양동삭개 술을 시행한 군에서는 $5.7 \pm 17.5 \mathrm{~dB}$ 로, 두 군 간에 통계적 으로 의미 있는 차이를 보이지 않았다 $(p=0.45)$.

\section{고 찰}

일반적으로 고실성형술은 중이강 내의 비가역적인 병변을 제거하고 청각의 개선을 목적으로 하며, 고실성형술 방법은 고막과 이소골의 상태에 따라 분류된다. ${ }^{1)}$ 이소골 연쇄가 정 상일 경우 중이의 병변을 제거한 후 고막을 재건하는 제 1 형 고실성형술의 경우 청력의 개선 정도는 약 $10 \mathrm{~dB}$ 이며, 76 $80 \%$ 에서 성공적인 수술 결과를 보이는 것으로 보고된다. ${ }^{4-6)}$ 본 연구에서도 $89 \%$ 에서 성공적인 수술 결과를 보여 이전의 보고들과 유사한 결과를 보였다.

이소골 연쇄가 손상될 경우에는 인공적인 방법으로 이소 골의 연쇄를 재건해야 한다. 인공이소골을 사용할 경우에는 정상적인 이소골의 연쇄에서 관찰할 수 있는 레버효과(lever action)는 소실되게 되며, 이러한 이유로 가능한 인공이소골 을 추골과 등골 사이에 위치하려는 노력이 필요하며, 이러한 경우가 인공구조물이 고막에 직접 접촉하는 경우와 비교하 여 기도골도차가 $20 \mathrm{~dB}$ 이내로 되는 경우가 더 높다고 보 고된다(67\% vs. $42 \%){ }^{7}{ }^{7}$ 본 연구의 경우에는 대부분의 환자 에서 가능한 추골을 이용하는 $\mathrm{Si}$ 수술을 시행하여, 두 군의 차이를 통계적으로 비교할 수 없었다. 그러나 추골이 너무 내측으로 전위되어 있거나 전방으로 전위되었을 경우에는 인 공이소골의 각도가 불량해지며 에너지 전달의 효율이 감소하 
며 재건된 이소골의 안정성이 약해지는 문제점이 생길 수 있다. 이러한 경우 고막긴장근의 건을 절제하는 방법을 사용하거 나 인공이소골이 고막과 직접 접촉하는 방법을 사용하기도 한다. 후자 $(\mathrm{Sc})$ 의 경우 인공이소골이 고막을 뜷고 탈출하는 부작용을 줄이고자 연골을 고막과 인공이소골 사이에 간 치시키는 방법이 추천된다. ${ }^{2)}$ Hydroxylapatite(HA) 인공이 소골로 침골을 대치한 경우( $\mathrm{Si}$ 군)에 술 후 기도골도차가 20 $\mathrm{dB}$ 이내인 경우는 75 83\%, HA 인공이소골로 침-등골을 대치한 경우(Fi군)는 50 66\%로 보고되며, HA 인공이소 골을 사용하여 고막과 등골 두부를 연결하여 이소골의 연쇄 를 재건한 경우는 32 84\%, HA 인공이소골을 사용하여 고막과 등골 족판을 연결하여 이소골의 연쇄를 재건한 경우 는 33 62\%로 보고되어 등골 두부가 있을 경우 청력 개선 의 효과가 더 크다. ${ }^{8-16)}$ 이러한 차이는 등골 족판에 직접 인 공이소골이 위치할 경우에는 이소골이 미끄러질 가능성이 높 으며, 등골의 두부에 의해 이소골 연쇄가 보다 안전하게 유 지되어 이러한 차이가 발생할 것으로 생각된다. ${ }^{2)}$

본 연구에서도 이러한 원칙에 따라 수술 방법을 결정하 였으며, 수술 후 $\mathrm{ABG}$ 가 $20 \mathrm{~dB}$ 이내의 성공적인 청력 개선 을 보인 경우는 Sc군에서는 $67 \%$, Si군에서는 $58 \%$, Fic군에 서는 $30 \%$ 로 이소골 연쇄의 복원을 통하여 통계적으로 유의 하게 청력의 개선을 얻을 수 있었다. 등골 상부구조가 남아 있을 경우에 보다 나은 청력 결과를 보였으나 각 수술 방법 에 따른 청력의 개선 정도는 통계적으로는 의미 있는 차이를 보이지 않았다.

이러한 결과는 기보고된 국내 연구에서의 결과와 유사하다. $\mathrm{Kim}$ 등 $^{17)}$ 에 의하면 $\mathrm{Sc}$ 고실성형술을 시행한 경우 $\mathrm{ABG}$ 가 $30 \mathrm{~dB}$ 이내인 경우는 $36 \%, \mathrm{Si}$ 고실성형술을 시행한 경우가 $67 \%$ 이며, Chon 등 ${ }^{18)}$ 에 의하면 $\mathrm{ABG}$ 가 $20 \mathrm{~dB}$ 이내의 경우 가 $\mathrm{Sc}$ 고실성형술에서 $29.2 \%, \mathrm{Si}$ 고실성형술에서 $43.5 \%$, Fic 고실성형술에서 $33.3 \%$ 였으며, Ryu 등 ${ }^{19)}$ 에 의하면 $\mathrm{ABG}$ 가 $20 \mathrm{~dB}$ 이내인 경우가 $\mathrm{Sc}$ 고실성형술에서 $25 \%, \mathrm{Si}$ 고실 성형술에서 $44 \%$ 로 보고된다.

인공이소골의 재료로는 뼈, 연골, 인공이소골 등 다양한 재료를 사용할 수 있으며, 본 연구에서는 HA로 만들어진 인공이소골을 사용하였다. HA는 뼈의 무기화합물 기질과 유 사한 인산칼슘으로 이루어진 바이오 세라믹으로서 생체적합 성 및 안정성이 확인되었다. ${ }^{20,21)}$ 고실성형술에 따른 재건 재 료 탈출의 빈도는 달라지며, 합성물질이 자가 이소골에 비해 이소골의 탈출률이 더 높은 것으로 알려져 있다. 장기간의 외 래 추적관찰을 통한 연구에 의하면 HA의 탈출률은 4 16\% 로 고막에 직접 접촉하여도 탈출할 가능성이 적다는 보고도 있으나, 연골의 간치술을 동시에 시행하는 경우 탈출률이 더
욱 감소하는 것으로 보고된다.,8-11) 본 연구에서는 자가이소 골과의 비교하는 연구가 아니지만, 인공이소골이 탈출된 경 우는 $\mathrm{Si}$ 군에서 6\%(4명/67명)에서 발생하였고, 4명 중 3명 에서 개방형 유양동삭개술을 시행한 군이었다. 이는 이미 보고 된 다른 연구의 결과와 유사하며, partial ossicular replacement prosthesis(PORP)로 이소골 성형술을 한 군에서는 4.3 8.8\%, total ossicular replacement prosthesis (TORP) 로 이소골 성형술을 한 군에서는 $12.5 \%$ 로 탈출 빈도가 보 고된다. ${ }^{17-19)}$

본 연구의 수술 후 결과를 요약하면, 수술 후 기도 청력역 치가 수술 전과 비교하여 $10 \mathrm{~dB}$ 이상 악화된 환자는 11 명 (6\%)이었으며, 대부분 $(94 \%)$ 의 환자에서 수술 후 청력이 개선되거나 차이를 보이지 않았다. 인공이소골이 탈출된 경 우는 $\mathrm{Si}$ 군에서 $6 \%$ 였다. 수술 후 $\mathrm{ABG}$ 가 $20 \mathrm{~dB}$ 이내의 성 공적인 청력 개선을 보인 경우는 $\mathrm{T} 1$ 군에서 $89 \%, \mathrm{Sc}$ 군에서 는 $67 \%$, Si군에서는 58\%, Fic군에서는 30\%이며, 수술 후 $\mathrm{ABG}$ 가 $30 \mathrm{~dB}$ 이내인 경우는 $\mathrm{T} 1$ 군에서 $95 \%$, Sc군에서 는 $67 \%, \mathrm{Si}$ 군에서는 $83 \%, \mathrm{Fic}$ 군에서는 $70 \%$ 였다. 장기간 의 관찰을 통한 청력의 변화가 보고되므로, ${ }^{4,7,19)}$ 환자의 장기 간의 관찰이 필요할 것으로 생각된다.

\section{Acknowledgments}

This paper was supported by Konkuk University.

\section{REFERENCES}

1) Wullstein $H$. Theory and practice of tympanoplasty. Laryngoscope 1956;66 (8):1076-93.

2) Javia LR, Ruckenstein MJ. Ossiculoplasty. Otolaryngol Clin North Am 2006;39 (6) :1177-89.

3) Kim HJ. Classification and hearing result reporting guideline in chronic otitis media surgery. Korean J Otolaryngol-Head Neck Surg 2006;49 (1) :2-6.

4) Cody DT, Taylor WF. Tympanoplasty: long-term results. Ann Otol Rhinol Laryngol 1973;82 (4) :538-46.

5) Claes J, Van de Heyning PH, Creten W, Koekelkoren E, Van Laer C, De Saegher D, et al. Allograft tympanoplasty: predictive value of preoperative status. Laryngoscope 1990;100 (12):1313-8.

6) Gerber MJ, Mason JC, Rambert PR. Hearing results after primary cartilage tympanoplasty. Laryngoscope 2000;110 (12):1994-9.

7) Goldenberg RA, Driver M. Long-term results with hydroxylapatite middle ear implants. Otolaryngol Head Neck Surg 2000;122 (5):635-42.

8) Grote JJ. Reconstruction of the middle ear with hydroxylapatite implants: long-term results. Ann Otol Rhinol Laryngol 1990;144:12-6.

9) Shinohara T, Gyo K, Saiki T, Yanagihara N. Ossiculoplasty using hydroxyapatite prostheses: long-term results. Clin Otolaryngol 2000;25 (4) : 287-92.

10) House JW, Teufert KB. Extrusion rates and hearing results in ossicular reconstruction. Otolaryngol Head Neck Surg 2001;125 (3):135-41.

11) Kobayashi T, Gyo K, Shinohara T, Yanagihara N. Ossicular reconstruction using hydroxyapatite prostheses with interposed cartilage. Am J Otolaryngol 2002;23 (4) :222-7.

12) Mangham CA, Lindeman RC. Ceravital versus plastipore in tympanoplasty: a randomized prospective trial. Ann Otol Rhinol Laryngol 
1990;99 (2 Pt 1):112-6.

13) Ho SY, Battista RA, Wiet RJ. Early results with titanium ossicular implants. Otol Neurotol 2003;24:149-52.

14) Gardner EK, Jackson CG, Kaylie DM. Results with titanium ossicular reconstruction prostheses. Laryngoscope 2004;114 (1):65-70.

15) Martin AD, Harner SG. Ossicular reconstruction with titanium proshesis. Laryngoscope 2004;114 (1) :61-4.

16) Yung M. Long-term results of ossiculoplasty: reasons for surgical failure. Otol Neurotol 2005;27 (1) :20-6

17) Kim BH, Lee GS, Ryu JM, Cho YC, Oh DH, Kang SH, et al. Comarison with hearing gains by the different methods of operation in the defect of malleus and incus. Korean J Otolaryngol-Head Neck
Surg 2003;46(7):555-8.

18) Chon KM, Goh EK, Lee IW. postoperative results of tympanoplasty type III and IV. Korean J Otolaryngol-Head Neck Surg 2002;45(5): 445-50.

19) Ryu CH, Yoon TH, Kim TS, Ahn JH, Kim JY. Postoperative results of ossiculoplasty over stapes head. Korean J Otorhinolaryngol- Head Neck Surg 2008;51 (3) :221-6.

20) Grote JJ. Reconstruction of the ossicular chain with hydroxyapatite prostheses. Am J Otol 1987;8 (5):396-401.

21) Wehrs RE. Incus interposition and ossiculoplasty with hydroxyapatite prostheses. Otolaryngol Clin North Am 1994;27 (4) :677-88. 